\title{
Exploring the use of the saw and seal method for mitigation of reflective cracking in composite pavements
}

\author{
S. A. Arhin ${ }^{1}$, E. C. Noel ${ }^{1}$, D. Wright ${ }^{1}$, W. Khan ${ }^{2}$ \& V. Hong ${ }^{3}$ \\ ${ }^{1}$ Howard University, USA \\ ${ }^{2}$ District Department of Transportation, USA \\ ${ }^{3}$ Federal Highway Administrative - DC Division Office, USA
}

\begin{abstract}
Reflective cracking, a common distress that affects composite highway pavements, is caused by cyclical movements of the underlying concrete base that is overlaid with hot-mix-asphalt in reaction to climatic and traffic conditions. A saw and seal method, which involves making saw cuts in the overlaying asphalt, (above the concrete joints) and sealing them with a compressible rubberized low modulus material, was studied for its effectiveness in mitigating reflective cracking in newly constructed pavements in Washington DC. In the $4 \frac{1}{2}$ year field study, the widths of the transverse and longitudinal saw-cuts made in the hot-mix-asphalt overlay were measured every three months at 22 saw-cut points. Multiple regression analyses and statistical tests of significance were conducted to determine the statistical relationship between the changes in mean daily air temperature, average daily traffic, pavement age and the variations of the sawcut widths. The interactions of changes in mean daily air temperature and ADT had a statistically significant impact on variations in transverse and longitudinal saw-cut widths, accounting for $95.7 \%$ and $91.4 \%$ of variations respectively. Pavement age also had a significant impact but was excluded due to multicollinearity with ADT. In conjunction with the statistical analyses, a visual condition comparison with a similar adjacent pavement section built without any saw-cut treatments showed that the saw and seal method effectively controlled reflective cracking in the composite pavement.
\end{abstract}

Keywords: reflective cracking, saw-cut sealant, pavement distress, hot-mixasphalt overlay. 


\section{Introduction}

Reflective cracking is a type of pavement distress that is prevalent in pavements consisting of an underlying concrete base overlaid with hot-mix-asphalt (HMA). In reaction to thermal and traffic loading, concrete - the pavement's base inherently expands, contracts, and vertically shifts, resulting in lateral and vertical movements, which consequently ruptures the bonded overlaying HMA at pavement joints. These cyclical movements of the pavement subsequently results in the upward progression of the rupture through to the driving surface, within a year to five years, or as short as a few months [1]. Reflective cracking, accelerated by freeze-thaw cycles, ultimately shortens a pavement's service life; facilitate creation of potholes, thus requiring premature maintenance or full pavement rehabilitation.

In response to the distress of pavements afflicted with reflective cracking, several state transportation departments have tried numerous mitigation techniques and the effectiveness of each has varied tremendously, depending on a number of factors; particularly climate conditions. One of these methods is the saw and seal method, which is a technique that creates incisions of uniformlyspaced saw cuts in the overlaying HMA surface directly above the underlying concrete joints or discontinuities in the concrete base and filling them with a rubberized low modulus sealant. The aim of this method is for the HMA overlay to accommodate the movements of the underlying concrete base by moving along with it instead of cracking at these joint locations. Saw-cuts are made across and along the direction of travel (transverse and longitudinal). Other commonly used mitigation techniques to prevent reflective cracking include the reinforcement of the HMA overlay with geosynthetic material, placing new asphalt directly on the distressed pavement and resurfacing with increased asphalt thickness, among others.

The success of each method should be viewed as being localized success and could be replicated applied elsewhere under very similar environmental and traffic conditions. Another prominent finding is that the success of the most frequently used reflective crack prevention methods tend to decrease with increasing traffic volumes. In fact, several methods fail after experiencing only medium-level traffic volumes [2].

With temperature, traffic volume, and pavement age recognized as the major factors that cause reflective cracking, the main objective of this study is to evaluate the saw and seal method in controlling reflective cracking by developing relationships between these factors and the changes of the saw-cut widths in the HMA overlay. This is achieved by statistical exploration from which a multiple regression model is created and the significance of the impact of each factor on changes in HMA saw-cut widths is determined. Using the multiple regression relationships developed along with an absolute visual pavement assessment comparison between the test and control sections, the level of effectiveness of the saw and seal method was determined.

In an attempt to find a successful strategy to minimize or prevent reflective cracking in composite pavements in Washington DC, the saw and seal method 
using a sealant that meets the criteria of ASTM D6690 Type 2 was evaluated in this research. The objectives of the research are to:

1. Determine if the magnitudes of transverse and longitudinal movements are equal.

2. Determine whether the effectiveness of the saw and seal method in controlling or preventing reflective cracking in Washington DC is dependent on individual and combinatory factors of air temperature, ADT, pavement age and the changes in widths of the saw-cuts in the asphalt overlay.

3. Explore the feasibility of developing a simple model from which the District Department of Transportation (DDOT) may determine potential crack growth under specific environmental and traffic loading conditions.

\section{Literature review}

Reflective cracking may occur in composite pavements as well as flexible pavements. However, reflective cracking in a composite pavement is more frequent and widely researched and documented. Reflective cracking are typically classified into two categories [3]:

1. Cracks caused by underlying joints in the concrete slab base

2. Cracks caused by underlying cracks either in the concrete base or old HMA overlay.

Reflective cracks occur due to a coupled effect of repetitive horizontal and vertical deflections at the underlying joints in composite (jointed) pavements or at the underlying cracks in original HMA layer that has been overlaid with additional HMA [4]. Figure 1 depicts the commonly known mechanisms of reflective cracking [3].

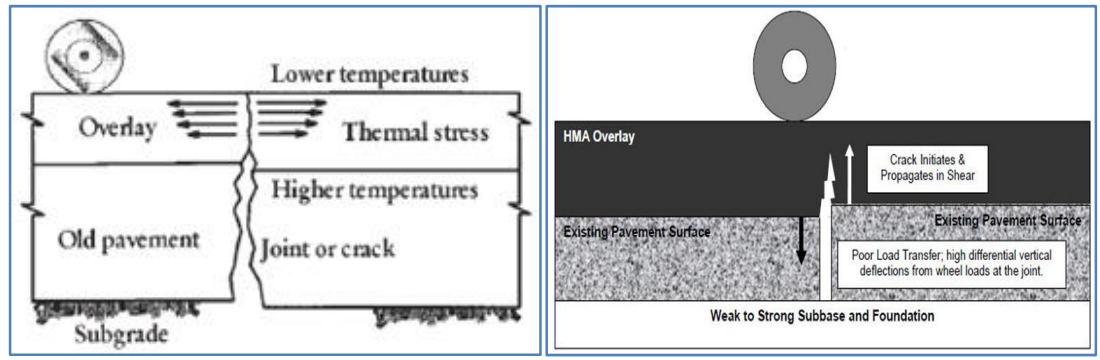

Figure 1: Common mechanisms of reflective cracking.

Saw and seal is a reflective crack mitigation technique that involves making incisions (transverse or longitudinal) of approximately half of an inch in width in a bituminous overlay and sealing them with rubberized modified asphalt (Figure 2). These joints in the bituminous overlay are located directly over the structural joints or cracks in the underlying concrete base. The saw and seal 
treatment is intended to accommodate the concrete's movement caused by its expansion and contraction in response to temperature changes. Sealing of the joints prevent the intrusion of moisture and incompressible materials, which could otherwise lead to pavement distresses such as rutting. The sealant's main characteristic is to be flexible in order to retain its adhesion to the walls of the joints during pavement expansion and contraction.

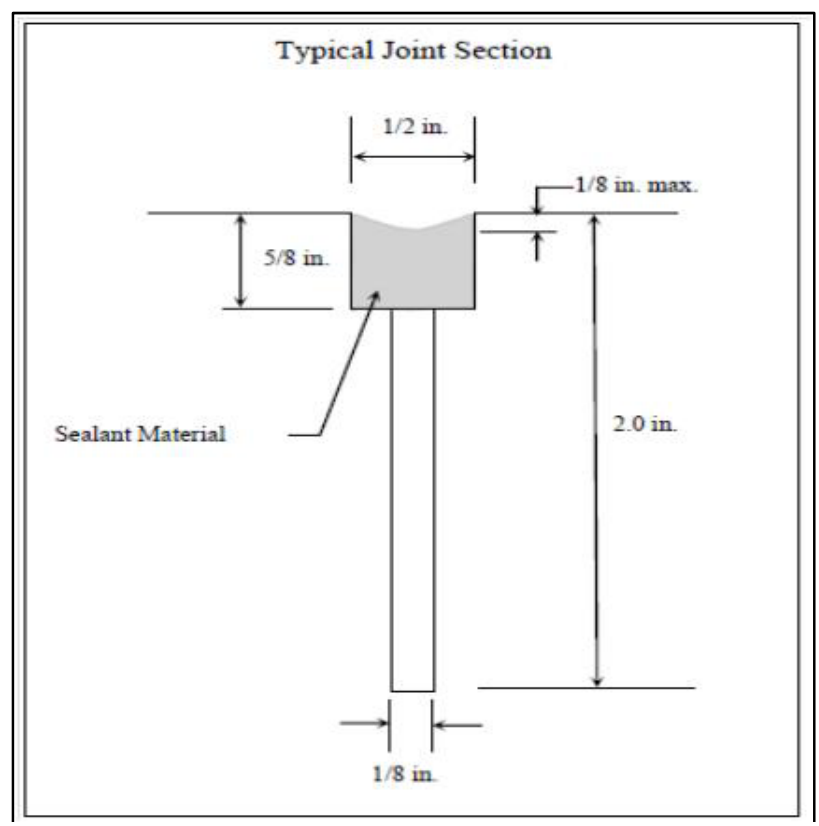

Figure 2: Detail of a typical saw-cut joint [10].

If underlying joint or crack movements cannot be accommodated by the overlay, the tensile stresses developed at the interface of the bituminous overlay and concrete base overcomes the tensile strength of the bituminous overlay and a crack is initiated. The frequency of these cracks throughout a concrete slab depends on the HMA overlay stiffness, traffic loading, and the friction properties at the interface between the overlay and underlying pavement layer [3]. The smaller joint spacing (slab length) suitably accommodates the stresses in the pavement and is generally more effective than longer ones. In New York, joint spacing distances as low as fifteen feet has been used with high levels of success in preventing reflective cracking, and in Minnesota thirty to fifty feet is the optimal joint spacing distance for the saw and seal method to be effective $[1,3]$.

In Minnesota and New York for example, it has been reported that the depth of the saw cut needs to be depth of at least $5 / 8^{\text {th }}$ inches in order for the underlying reflective cracks to coincide with the HMA overlay joints [3].

In Louisiana, the saw and seal method used on 15 composite pavements were evaluated for their cost-effectiveness and effectiveness in reducing reflective 
cracking [5]. The sections, monitored for a period of six or more years, experienced average annual daily traffic (AADT) ranging from 1,800 to 50,250, along with varying climate conditions. In the northern part of the state temperatures varied between $18^{\circ} \mathrm{F}$ and $106^{\circ} \mathrm{F}$ in the winter, and in the southern part of the state, temperatures varied between $46^{\circ} \mathrm{F}$ and $100^{\circ} \mathrm{F}$. Saw cuts made in the HMA overlay were both transverse and longitudinal. The study found that the saw and seal method was an overall success in increasing the service life of the pavement [5]. Seven test sections indicated an increase in service life ranging from 4 to 12 years and six of the test sections indicated an increase in service life of 3 years, resulting in an expected average increase in service life of 4 years. The study also found that the saw and seal method is a cost effective technique but is most cost-effective on pavements that experience low to medium traffic volumes.

In North Dakota, a study on a composite pavement test section that consisted of 54 sawed and sealed joints were conducted to determine its effect on controlling reflective cracking [6]. That study began in 1994 and yearly evaluations were performed until 2001. The pavement consisted of an underlying concrete base that had very little transverse and longitudinal cracking with a four-inch thick HMA overlay. Joints in the HMA overlay were sawed directly over the joints in the concrete base at 28 feet apart. The study found that all joints were in good condition and they experienced no adhesion failure between the sealant and the sidewalls of the joints despite extreme temperature cycling [6]. The findings also suggested that the saw and seal method is effective when joints in the HMA overlay are located within one inch of the underlying concrete joint. The saw and seal method was found to be successful since after seven years, the test section experienced no cracking even though 59 percent of the shoulders at the joints experienced reflective cracking.

This paper expands previous work on saw-cut methods for mitigating reflective cracking by examining relationships between the increase in saw-cut widths and changes in temperature, ADT and pavement age. The freeway site selected for this research was new composite pavement.

\section{Methodology}

Based on the literature review, climate has the most significant impact on reflective cracking. Almost all studies that were conducted in warmer climates produced more effective results than the studies conducted in areas that experienced drastic temperature variations $[2,7]$. Similarly, studies conducted in Louisiana, Nevada, Massachusetts, and Virginia indicated that traffic volume also influences the progression of reflective cracking. Considering these observations, air temperature (measured in degrees Fahrenheit) and ADT were chosen as two variables to be used in evaluating their impact on longitudinal and transverse saw-cuts in preventing reflective cracking. 


\subsection{Hypothesis and visual observations}

In order to assess the effectiveness of the saw and seal method in the prevention of reflective cracking, the impacts of changes in daily mean air temperature, ADT, and pavement age on transverse and longitudinal HMA saw-cut widths were determined. The following hypotheses were developed:

1. It is hypothesized that changes in average transverse saw-cut widths are related to mean daily air temperature, average daily traffic (ADT), and pavement age. The hypotheses are defined as follows:

$$
\begin{aligned}
& \mathrm{H}_{0}: \mathrm{X}_{\text {avg }} \neq f\left(\Delta^{\circ} \mathrm{F}, \text { ADT, age }\right) \\
& \mathrm{H}_{1}: \mathrm{X}_{\text {avg }}=f\left(\Delta^{\circ} \mathrm{F}, \text { ADT, age }\right)
\end{aligned}
$$

$\begin{array}{rll}\text { where: } & \Delta^{\circ} \mathrm{F}= & \text { Changes in daily mean air temperature } \\ \text { Age }= & \text { Age of the pavement } \\ \text { ADT }= & \text { Average daily traffic } \\ \mathrm{X}_{\text {avg }}= & \text { Average change in width of HMA saw-cut over } \\ & \text { transverse concrete joints }\end{array}$

2. It is hypothesized that changes in average longitudinal saw-cut widths are related to mean daily air temperature, average daily traffic, and pavement age. The hypotheses are defined as follows:

$$
\begin{array}{ll}
\mathrm{H}_{0}: \mathrm{L}_{\text {avg }} \neq f\left(\Delta^{\circ} \mathrm{F}, \text { ADT, age }\right) \\
\mathrm{H}_{1}: \mathrm{L}_{\text {avg }}=f\left(\Delta^{\circ} \mathrm{F}, \text { ADT, age }\right) \\
\text { where } \mathrm{L}_{\text {avg }}=\quad \begin{array}{l}
\text { Average change in width of HMA saw-cut over } \\
\text { longitudinal concrete joints }
\end{array}
\end{array}
$$

3. Visual Observations: By visual inspection, it is hypothesized that reflective cracking will be mitigated more at the treated (experimental) section compared with the untreated (control) section.

\subsection{Data collection}

The experiment was conducted on North Capitol Street, which is a heavily traveled three-lane divided roadway oriented in the north to south direction, that links Washington DC to Silver Spring, Maryland. North Capitol Street carries an ADT of approximately 30,000 vehicles. The research site, shown in Figure 3, is approximately 150 feet long and consists of fifteen transverse and seven longitudinal HMA saw-cut observation points. The transverse saw cuts covered all three lanes and were equally spaced at 30 feet and the longitudinal saw-cuts are located along the centerline between each southbound lane. The HMA sawcuts are filled with sealant to the exact level of the pavement. The adjacent northbound lanes, constructed at the same time as the experimental section, but without sawing and sealing, were used for comparison purposes. It was assumed that the ADT for both the northbound and experimental sections was the same.

Three types of data were collected on a quarterly basis: HMA saw-cut widths (for transverse and longitudinal), average daily traffic; mean daily air temperature, and pavement age. These data were obtained by field observations and historical records from DDOT. 


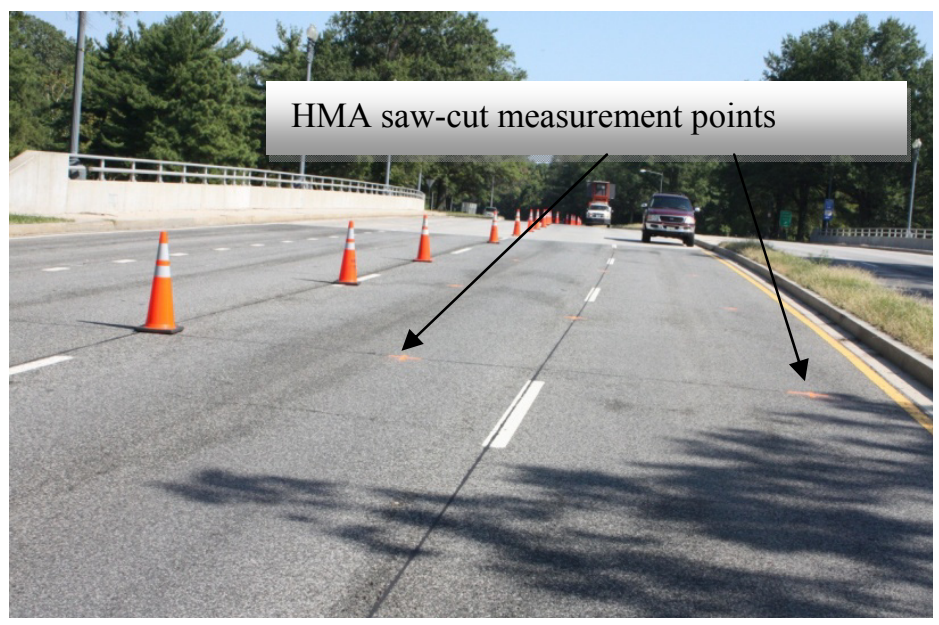

Figure 3: $\quad$ Saw-cuts treated pavement joints.

A field reconnaissance was conducted to select the road segment for the study and to locate the joints of concrete slabs fir the study. The installation of sawcuts in the HMA was conducted after pavement construction in order to establish individual measurement points of each saw-cut located in each lane. Saw-cut widths 0.44 to 0.60 inches were made along the longitudinal and transverse joints in the travel lanes. The joints were sealed, and subsequently, 22 points for measuring joint expansion were selected: 7 on longitudinal and 15 on transverse joints. The points for measurement were marked with spray-painted for ease of re-identifying upon repeat visits for measuring their widths. On each saw-cut measuring day, the mean air temperature for Washington DC was recorded from the National Climatic Data Center. The data collection span a $4 \frac{1}{2}$ year period, from May 2006 to December 2010.

Visual observations of the experimental section and the adjacent "control" northbound roadway section were conducted during each field visit. Distress to the pavement surfaces of both sections was noted and photographed.

The average of the fifteen initial transverse saw-cut width and the seven initial longitudinal saw-cut widths were calculated. These were used as initial observation values for transverse and longitudinal saw-cut widths respectively. The change in daily mean temperature in degrees Fahrenheit for the day of the data collection was obtained by subtracting the initial air temperature of the beginning day of the project from the average temperatures recorded for each data collection day. 


\section{Results}

\subsection{Hypothesis no. 1}

It was hypothesized that the changes in average transverse saw-cut widths are related to temperature, ADT, and pavement age. Table 1 presents the results of the statistical analysis using the changes in average transverse HMA saw-cut width as the dependent variable. The impact of each independent variable (mean daily air temperature, ADT, and pavement age) on the dependent variable (changes in HMA saw cut widths) at each stage of model building are discerned from the R square, F-ratio, standard of error in prediction, and the $p$-values. A $p$ value of less than 0.05 indicates statistical significance. From the results of the analysis, the alternative hypothesis that the changes in average transverse HMA saw-cut width is related to changes in mean daily air temperature and ADT cannot be rejected.

Table 1: $\quad$ Statistical summary of multiple regression model for changes in transverse HMA Saw-cut widths.

\begin{tabular}{|c|c|c|c|c|}
\hline \multicolumn{3}{|c|}{ Model Summary } & \multicolumn{2}{c|}{ ANOVA } \\
\cline { 1 - 3 } $\begin{array}{c}\text { Independent } \\
\text { Variables } \\
\text { in Model }\end{array}$ & $\begin{array}{c}\text { Unstandardized } \\
\text { Coefficients }(\boldsymbol{b})\end{array}$ & $\begin{array}{c}\text { Beta } \\
(\boldsymbol{\beta})\end{array}$ & F-Ratio & -value \\
\cline { 1 - 3 } $\begin{array}{c}\text { Change in Mean } \\
\text { Daily } \\
\text { Temperature }\end{array}$ & -0.0005251 & -0.059 & \multirow{2}{*}{89.079} & 0.000 \\
\cline { 1 - 2 } $\begin{array}{c}\text { Change in Mean } \\
\text { Daily } \\
\text { Temperature }\end{array}$ & $1.613 \times 10^{-5}$ & 0.057 & & \\
\hline ADT $^{2}$ & $6.983 \times 10^{-10}$ & 0.930 & & \\
\hline
\end{tabular}

Note: $R^{2}=0.411$ and Standard Error of the Estimate $=0.043$ inches

\subsection{Hypothesis no. 2}

It was hypothesized that the changes in the average longitudinal saw-cut widths are related to temperature, ADT, and pavement age. Presented in Table 2 is the summary of the results of the ANOVA multiple regression analysis using the changes in average longitudinal HMA saw-cut width as the dependent variable. The viability of the model was derived from the F-ratio and the $p$-values. A $p$-value of less than 0.05 for the associated F-statistic indicates statistical significance of the model. Based on the results of the analysis, the alternative hypothesis that the changes in average longitudinal HMA saw-cut width is related to changes in mean daily air temperature and ADT cannot be rejected. 
Table 2: $\quad$ Statistical summary of multiple regression model for changes in longitudinal HMA Saw-cut widths.

\begin{tabular}{|c|c|c|c|c|}
\hline \multicolumn{3}{|c|}{ Model Summary } & \multicolumn{2}{c|}{ ANOVA } \\
\cline { 1 - 2 } $\begin{array}{c}\text { Independent } \\
\text { Variables } \\
\text { in Model }\end{array}$ & $\begin{array}{c}\text { Unstandardized } \\
\text { Coefficients (b) }\end{array}$ & $\begin{array}{c}\text { Beta } \\
(\boldsymbol{\beta})\end{array}$ & F-Ratio & -value \\
\cline { 1 - 3 } $\begin{array}{c}\text { Change in Mean } \\
\text { Daily Temperature }\end{array}$ & 0.000125 & 0.033 & \multirow{2}{*}{42.457} & 0.000 \\
\cline { 1 - 2 } $\begin{array}{c}\text { Change in Mean } \\
\text { Daily Temperature }\end{array}$ & -0.00001037 & -0.084 & & \\
\cline { 1 - 2 } ADT $^{2}$ & $3.297 \times 10^{-10}$ & 1.014 & & \\
\hline
\end{tabular}

Note: $R^{2}==0.489$ and Standard Error of the Estimate $=0.026$ inches

\subsection{Visual observations}

Visual inspections of the experimental and control sites were conducted over the period of the study. As shown in Figure 4, the test section, which was treated with the saw-cut sealant was found to be in good condition compared with the untreated section. It was also observed that the experimental section experienced minimal reflective cracking (or of low severity) while the control section experienced significant cracks as shown in Figure 4.

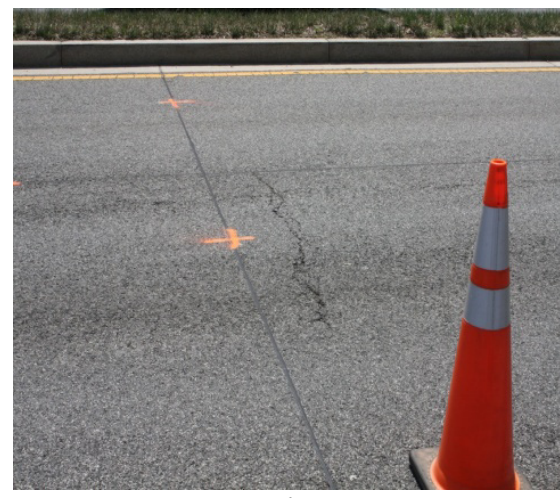

Experimental Section

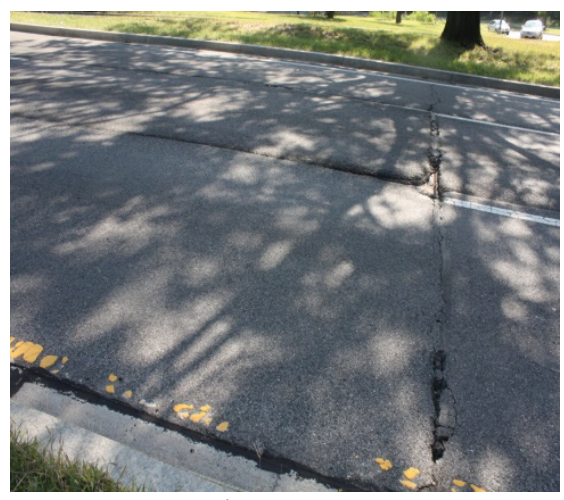

Control Section

Figure 4: Visual inspection of experimental and control sections.

\subsection{Regression model for freeways/interstates}

From the results of the multiple regression analyses presented in Sections 4.1 and 4.2 (i.e., Tables 1 and 2), the following regression models were respectively 
developed for the average transverse and longitudinal saw-cut widths which were measured over a four-and-a-half year period:

$T_{\text {saw-cut width }}=$ where$$
\left(-0.0005251 \Delta^{\circ} \mathrm{F}+0.00001613 \Delta^{\circ} \mathrm{F}^{2}\right)+\left(6.983 \times 10^{-10} \mathrm{ADT}^{2}\right)
$$

$T_{\text {saw-cut width }}=$ Change in Average Transverse Saw-cut Width

$\Delta^{\circ} \mathrm{F}=$ Change in Mean Daily Air Temperature

ADT $=$ Average Daily Traffic

Age $=$ Pavement Age

$L_{\text {saw-cut width }}=\left(0.000125 \Delta^{\circ} \mathrm{F}-0.00001037 \Delta^{\circ} \mathrm{F}^{2}\right)+\left(3.297 \mathrm{X} 10^{-10} \mathrm{ADT}^{2}\right)$

where

$L_{\text {saw-cut width }}=$ Change in Average Longitudinal Saw-cut Width

\section{Discussion and conclusion}

This research explored the effectiveness of the saw and seal method in mitigating the impacts of reflectively cracking in a composite pavement. Based on the results of the statistical analyses and the visual assessment of the test and comparison sections, the saw and seal method effectively controlled reflective cracking. Confirming this finding is the statistically significant relationship found between the interaction of air temperature, ADT, and the changes in the saw-cut widths; which explained $98.1 \%$ and $94.4 \%$ of variations in transverse and longitudinal movement at the saw-cuts respectively. This finding indicated that the variations in saw-cuts did not occur by chance but due to the impacts of air temperature, and ADT; further indicating that the saw and seal method is an effective measure in mitigating reflective cracking.

The standardized residual values of the models indicate that the models accurately represent the data and relationships among variables. The absolute values of the maximum and minimum standardized residuals of both models are less than 2.58 , indicating that more than $99.9 \%$ of the data (the entire data set) is described by the model and hence no outliers are present and all values are accurately represented by the model. In addition, the predictive accuracies of both models are $98.9 \%$ and $94.4 \%$ with standard errors in prediction of 0.025 and 0.022 inches respectively, which are relatively small in comparison to typical HMA-saw-cut widths.

\section{Acknowledgement}

Appreciation is extended to the District Department of Transportation (DDOT) for supporting this study. DDOT supported the research efforts with funding and the provision of traffic control during field data collection. 


\section{References}

[1] Mallela, J., Von Quintus, H., \& Farina, J. (2008). Observations, Modeling, and Mitigation Related to Reflective Cracking on Composite Pavements in New York City. Transportation Research Record: Journal of the Transportation Research Board (No. 2084), 124-133.

[2] Von Quintos, H., Lytton, R. L., Mallela, J., Weiss, W., \& Shen, S. (2009). Techniques for Mitigation of Reflective Cracks. Final Report AAPTP 05-04. Champaign: Applied Research Associates, Inc.

[3] Janisch, D. W., \& Turgeon, C. M. (1996). Sawing and Sealing Joints in Bituminous Pavements to Control Cracking. St. Paul: Minnesota Department of Transportation.

[4] Turo, M., Worden, M., \& Bennert, T. (2009). Field and Laboratory Forensic Analysis of Reflective Cracking on Massachusetts Interstate 495. Transportation Research Record: Journal of the Transportation Research Board (No. 2126), 27-38.

[5] Elseifi, Mostafa E, Rakesh Bandaru, Zhongjie Zhang, and Said Ismail. "Field Evaluationand Cost-Effectiveness of the Saw and Seal Method to Control Reflection Crackingin Composite Pavements." Transportation Research Board. Washington DC: Lousianna State University, 2011.

[6] Horner, R. (2001). Evaluation of Saw and Seal over the Overlaid Existing Concrete Joints. Final Report, Project NH-3-002(040)212. Materials and Research Division, North Dakota Department of Transportation.

[7] Cleveland, G. S., Button, J. W., \& Lytton, R. L. (2002). Geosynthetics in Flexible and Rigid Pavement Overlay Systems to Reduce Reflection Cracking. Austin: Texas Transportation Institute.

[8] Mukhtar, M. T., \& Dempsey, B. J. (1996). Interlayer Stress Absorbing Composite for Mitigating Reflection Cracking in Asphalt Concrete Overlays. Springfield: Illinois Department of Transportation.

[9] Morse, A. A., \& Green, R. L. (2003). Pavement Design and Rehabilitation. In K. J. Boedecker, Highway Engineering Handbook: Building and Rehabilitating the Infrastructure (pp. 223-237). Columbus: McGraw-Hill Companies, Inc.

[10] Colson, S. (2008). Comparison of Saw and Seal Procedure and Performance Grade Binder to Minimize Thermal Cracking. Technical Report 00-19. Augusta: Transportation Research Division, Maine Department of Transportation.

[11] Reay, S., Appleyard, M., Van Dam, T., \& Sandberg, B. (1999). Sealing and Filling of Cracks for Bituminous Concrete Pavements. Selection and Installation Procedures. Lansing: Michigan Department of Transportation.

[12] Hall, K. T., Correa, C. E., \& Simpson, A. L. (2003). Performance of Flexible Pavement Maintenance Treatments in the Long-Term Pavement Performance SPS-3 Experiment. Transportation Research Record (1823). 